\title{
Effects of Retrieval Vocabulary Instruction on Academic Reading Comprehension
}

\author{
Kubra Saygili a * (D) \\ ${ }^{a}$ Istanbul Şehir University, Istanbul, 34662, Turkey
}

Received 20 July 2017 | Received in revised form 23 August 2017 | Accepted 8 October 2017

\begin{abstract}
This study aimed to explore the effects of retrieval vocabulary instruction on academic reading comprehension of 40 participants at the School of Foreign Languages at Istanbul Şehir University. According to Barcroft (2015) retrieval vocabulary is defined as the learners' ability to recall the words when they need to produce or use them accordingly. The independent variable is retrieval vocabulary instruction and the dependent variable is academic reading comprehension. A pre-test was administered in the first week of module in order to see the academic reading comprehension level of the participants. A treatment of retrieval vocabulary instruction was given for seven weeks. Later a post-test was administered in week eight so as to observe whether retrieval vocabulary instruction has any positive effect on academic reading comprehension or not. SPSS was used in order to analyze the data, and graphically detailed analysis of the reading comprehension tests are shown at the end. A Pair Sample statistics was used. The findings of the current study indicated that according to significance levels and the means of the both of the groups, it can be said that there is a significant change between two test scores taken at different times from the same groups of participants. Thus, it can be concluded that the treatment of the retrieval vocabulary instruction was beneficial for the participants since it increased their reading comprehension scores.
\end{abstract}

(C) 2017 EJAL \& the Authors. Published by Eurasian Journal of Applied Linguistics (EJAL). This is an open-access article distributed under the terms and conditions of the Creative Commons Attribution license (CC BY-NC-ND) (http://creativecommons.org/licenses/by-nc-nd/4.0/).

Keywords: Retrieval Vocabulary Instruction, Academic Reading Comprehension, Vocabulary Teaching, Vocabulary Instruction, Reading Comprehension

\section{Introduction}

\subsection{Statement of the problem}

This study aimed to explore the effects of "retrieval vocabulary instruction" on academic reading comprehension of 40 participants of the School of Foreign Languages at Istanbul Şehir University. The independent variable is retrieval vocabulary instruction and the dependent variable is academic reading comprehension. According to Grabe (2007), reading is defined as a perplexing ability to interpret, infer and construct sense or understanding from a text. Reading is the

\footnotetext{
* Kubra Saygili, Tel.: +905392999908

E-mail address: kubrasaygili@sehir.edu.tr

http://dx.doi.org/...
} 
combination of reciprocal procedures between the reader and the text. Reading is a number of interactive processes between the reader and the text, in which readers are required to utilize their insight to work, to make, and to build meaning (TESOL, 2017). Vocabulary has also different definitions in the literature of applied linguistics. According to TESOL, vocabulary can be defined as the expressions of a dialect which consists of single items and phrases or chunks of several words which convey a particular meaning.

Reading comprehension for $\mathrm{C} 1$ proficiency level of students is that 'students can understand in detail lengthy, complex texts, whether or not they relate to their own area of specialty provided they can reread difficult sections (Council of Europe, 2001). Thus, the theoretical definition of the current study will be based on the abovementioned definition. As for the theoretical definition of the vocabulary for $\mathrm{C} 1$ proficiency level of students the following definition will be considered; "Students have a good command of a broad lexical repertoire allowing gaps to be readily overcome with circumlocutions; little obvious searching for expressions or avoidance strategies. Good command of idiomatic expressions and colloquialisms" (Council of Europe, 2001). As it can be understood, above mentioned are theoretical definitions of the current study. These are mentioned to define the variables of the study in a detail way and also to familiarize the reader with $\mathrm{C} 1$ reading proficiency level of students since the participants' level is $\mathrm{C} 1$. As seen above, the significance of these operational definitions for the study is that it helps identifying theoretical constructs and develop multiple operational definitions of each. Illustrating the operational definitions also shows how the process is done.

There are different theoretical definitions for retrieval vocabulary instruction in the literature. Thorne (2016) states that there are some retrieval strategies that can be followed by language teachers. The strategies are as follows; Encoding and Retrieval Practice, Retrieval Cues and the Encoding Specificity Hypothesis, and Mnemonic Methods. The first one includes retrieval practice along with engaging in activities that are helpful for the recall of the stored words. To illustrate, using the previously learnt vocabulary in a sentence. The second one is related to the visual images along with the associations of the words. The last one, Mnemonic Method is related to the both visual imagery and verbal elaborations that will enable the learner to recall the vocabulary easily. The other recommended retrieval strategies; Association StrategySame-Sounds Cue, Familiar-Word Cue, are proposed by; German and Schwanke, (2009). Laufer (2005) suggested that note cards consist of part of speech, synonyms, antonyms, sample sentence is also beneficial for retrieval vocabulary instruction. Removal of the written input shared and split information tasks are thought to be found effective in retrieval vocabulary instruction (Nation, 2001).

There are also other notions related to retrieval strategies. According to Baddeley (1990), retrieval strategies help learners to enhance their vocabulary strategies in order to call for the production of words which are currently learned. Baddeley (1990) also discussed the types of retrieval words by defining them as receptive or productive. Baddeley emphasizes the significance of retrieval by stating that 
simultaneous presentation of form and meaning do not help retrieval at all. Another definition is put forward by Min (2013) suggesting that efficient input is always before the efficient output. As it is cited in Barcroft (2015) retrieval vocabulary is defined as the learners' ability to recall the words when they need to produce or use them accordingly. Barcroft (2015) also holds the opinion that retrieval is a cognitive entry process for information which already exists in the individual brain. Furthermore, this definition is related to the previous experience or knowledge of the learner. Therefore, as mentioned before the significance of input and output are worth discussing here once again. Lastly, as Takac (2008) states it is very important to clarify retrieval vocabulary strategies for the knowledge of vocabulary since there is a strong connection between the vocabulary knowledge and retrieval words. Another significant issue worth mentioning is related to factors affecting the retrieval of lexical items. Thus, Takac (2008) also notes that there are various factors that affect the lexical item retrieval and its efficacy such as; acquiring time, cognitive abilities of the learners, L2 level, and learning styles.

With regard to the reading comprehension theoretical definition, Grabe (2007) claims that reading comprehension is the combination of various sub-components or skills in order to identify the words effectively along with the word recognition. Grabe (2007) also states that reading comprehension has a range of strategic processes and underlying cognitive skills (e.g., setting goals, changing goals flexibility, and monitoring comprehension) by interpreting and evaluating the text. Perfetti and Stafura (2014) divided reading comprehension into two levels which are; situational and text level. Previous literature attempted to define reading comprehension with the same terms, but different interpretations of situation model and text model. According to Grabe (2009), text model is defined as a combination of the information with active meaning elements whereas situation model includes both explicitly learned knowledge along with the prior knowledge. Thus, it can be said that situation model has more engaging interpretation since it involves mental representations of the reader. Another important theory for reading comprehension is the C-I (Construction-Integration) theory which is about consolidation of both top-down and bottom-up processes of reading (Kintsch, 1988).

\subsection{Justification}

It is known that reading comprehension and teaching vocabulary have been a subject of many previous research. There are many studies in the literature on reading comprehension/reading strategies and vocabulary but to date, there are not many studies on academic reading comprehension along with retrieval vocabulary instruction. To illustrate, Williams (2010) conducted a study with EFL learners in Saudi Arabia to see if certain reading strategies are effective in terms of reading comprehension. The findings of the study illustrated that there was no significant relationship between the reading strategies and the level of reading comprehension. As Chaury (2015) points out in meta-analysis study, strategy instruction on reading 
comprehension for L2 was found to be significantly correlated regardless of the length of the treatment.

Numerous studies have also attempted to explore the effects of vocabulary learning through extensive reading. In Nation's (2015) study, the significance of extensive reading was emphasized, thus the article aimed to explore the different set of vocabulary learning principles that affect extensive reading by indicating much informative knowledge regarding extensive reading. Senoo and Yonemoto (2014) conducted a similar study with Japanese participants in order to explore vocabulary acquisition via extensive reading. According to the findings of the Senoo and Yonemoto's study, extensive reading was found to be beneficial when it is taught with specific vocabulary acquisition strategies. What makes this study unique is that it focuses on non-western languages rather than English or other western, European languages. Such studies, however, fail to address the academic reading comprehension along with retrieval vocabulary instruction. Thus, the reason why I wanted to conduct such a study is that most studies on reading comprehension are generally focused on general comprehension rather that academic. Hence, another important reason regarding why this study is conducted is to fill the gap in this field. Most of the previous literature generally focused on 'vocabulary size, input and their effect on reading performance' or 'vocabulary acquisition and extensive reading'. The study that contributed to the field in the literature is conducted by Schmitt (2011). Schmitt's (2011) study mainly focused on the size of vocabulary and its relationship with the text comprehension. Schmitt's study was conducted with a large sample (611) who were from different educational contexts. The findings of Schmitt's study indicated that there has been a continuous correlation between the known vocabulary and the reading comprehension. It can also be concluded from Schmitt's (2011) study that when the percentage of known words in a text increases the level of reading comprehension increases as well. All these things considered above, these studies support the notion that reading comprehension is highly related and integrated with vocabulary learning.

\subsection{Significance}

The present study would hopefully be particularly valuable to both researchers and teacher-researchers whose educational context has a curriculum of teaching English in an academic context. The present study would also make several noteworthy contributions to the field by involving participants from a different educational background including both Turkish Arab students. Although thorough research has been carried out on reading instructions, reading comprehension, and vocabulary input, no single study is reported which explores the relationship between both academic reading comprehension and retrieval vocabulary instruction. Much of the current literature on reading comprehension paid attention to the specific reading strategies, learner styles, and their influence rather than academic reading comprehension and retrieval vocabulary instruction. As Brown, Waring, and Donkaewbua, (2008) presented in their papers, English vocabulary was closely related 
to different learning strategies such as reading, while listening, story listening and so forth. The study also indicated the significance of incidental vocabulary learning which is tested via unprompted recall teaching techniques. Another similar study is conducted by Gürses and Bouvet (2016) in order to investigate the learning styles and reading comprehension of the students with regard to reading strategies. The Kolb Learning Style Inventory was taken into consideration in this study. Surprisingly there has been a negative correlation between learning strategies and reading comprehension both for Australians and Turkish participants. However, large sampled studies can be conducted related to the investigation of these two variables. It has commonly been assumed by many vocabulary experts (Hirsch, 2003, Chall \& Jacobs, 2003) that readers should have knowledge of $90 \%$ of the words in the reading passage in order to have a high level of reading comprehension. That is to say, reading comprehension and the vocabulary levels are highly integrated and correlated with each other. Thus, the above-mentioned studies clearly indicate that there is a significant level of positive relationship between vocabulary and reading.

As previously mentioned, the existing literature on different reading strategies is detailed, but failed to address both academic reading comprehension and retrieval vocabulary instruction. The study to address to show the relationship between L2 reading comprehension and newly learned lexical items was conducted by Pulido (2004). In this detailed investigation of L2 reading comprehension and vocabulary, Pulido (2004) concluded that lexical achievement via written recall in their L1 had a positive role and relationship with regard to reading comprehension. However, it is important to clarify here that there was an effect of topic familiarity as well. A more comprehensive study by $\mathrm{Hu}$ and Nation (2000) included a different variable to their studies called 'unknown vocabulary density'. The purpose of Nation's study is to make an attempt to illustrate the effect of unassisted reading for pleasure which means, the learners would not be interrupted to check the meanings of the unknown words during the reading process. The cue is given to participants via multiple-choice tests and written recall texts. Nation's study has broken the tradition by including different concepts to the current study as mentioned above. The findings of the study showed that participants need to know $3 \%$ of the words in the passage so as to benefit from the unassisted comprehension of a text. Having mentioned the effect of assisted reading, Shen's (2013) influential paper on the effect of dictionary use in EFL reading and vocabulary knowledge is worth discussing. In this study, Shen (2013) questioned and touched upon many significant things; such as vocabulary size, word knowledge, dictionary use and reading performance. The findings of the study indicate that the size of the vocabulary along with knowledge of vocabulary is positively correlated with reading comprehension, however according to his paper; knowledge of vocabulary has more positive impact than vocabulary size has with regard to reading comprehension. All studies reviewed here, clearly indicate that there is a relationship between reading comprehension and vocabulary knowledge/ vocabulary size.

\subsection{Research Questions}


This study aimed to explore the effects of retrieval vocabulary instruction on academic reading comprehension at the School of Foreign Languages at Istanbul Şehir University with the following research question below;

1. Does retrieval vocabulary instruction have an effect on academic reading comprehension?

\subsection{Research Hypotheses}

Retrieval vocabulary instruction has a positive effect on academic reading comprehension.

\subsection{Limitations and Delimitations}

The potential delimitation of this study could be related to the participants and sampling since there may be mortality at the end of the seventh week during the posttest.

\section{Method}

\subsection{Participants:}

Participants are 40 students at Istanbul Sehir University. They are selected following convenience sampling procedure from different sociocultural backgrounds. Their age ranges between 18 and 23 and their language proficiency is considered to be around C1 within the CEFR. In addition, STEP (Şehir Test of English Proficiency Exam), TOEFL are administered while assigning the students' level at the beginning of the semester. There are also accepted exams by the School of Foreign Languages such as; TOEFL IBT, Cambridge ESOL, Cambridge BEC, Cambridge BULATS, TOEIC, SAT, ACT, U Michigan, GRE, CEF, PTE.

The detailed score range in these exams are as follows;

TOEFL IBT: 79 (no requirement for the band scores)

Cambridge ESOL: FCE-A

Cambridge BEC: Vantage-B

Cambridge BULATS: 70

TOEIC: 735

SAT Read\&Wri.: 550

ACT Read\&Wri.: 22

U Michigan: ECCE-C-650 (low pass)

GRE Verbal: 450 (old system) - 150 (new system)

CEF: B2

PTE Academic: 55 
See Table 1 for clear and detailed background information of the participants.

Table 1: Background Information of the Participants

\begin{tabular}{llcc}
\hline Related Information & $\begin{array}{c}\text { Experimental } \\
\text { Group } \\
(\mathrm{N}-20)\end{array}$ & $\begin{array}{c}\text { Comparison } \\
\text { Group } \\
(\mathrm{N}-20)\end{array}$ \\
\hline \multirow{2}{*}{ First Language } & Turkish & 18 & 17 \\
& Arabic & 2 & 3 \\
\hline Department & Science/ Technology & 8 & 9 \\
& Social Science & 7 & 6 \\
& School of Law & 5 & 5 \\
\hline
\end{tabular}

\subsection{Procedure}

The research for the current study lasted eight weeks. The pre-test is administered in the first week of the module in order to see the academic reading comprehension level of participants. Treatment of retrieval vocabulary instruction is given for seven weeks. The retrieval vocabulary instruction is given regarding the techniques given in the literature review. Laufer (2005) suggested that note cards consisting of part of speech, synonyms, antonyms, sample sentences are also beneficial for the retrieval vocabulary instruction. Removal of the written input shared and split information tasks are thought to be found effective in retrieval vocabulary instruction (Nation, 2001). Thus, the above mentioned techniques are used in the current study.

The PPTs or the flash cards are prepared before the class from the list of target Vocabulary. The PPTs have a wide range of information on them including synonyms, antonyms, sample sentences and part of speech. The PPTs are shown to the students at the beginning of the lesson every Friday, and students are required to make up sentences by using these words on the board. Another requirement is related to producing their own sentences via using a context or paragraph. When participants learn the words from the PPTs they are required to form groups or pairs and create their own sentences within a context. The retrieval vocabulary instruction procedure lasted seven weeks. Later post-test is administered in the week eight so as to observe whether retrieval vocabulary instruction has any positive effect on academic reading comprehension or not. (See Appendix A for detailed information on the Vocabulary Instruction and Appendix B for the targeted words.)

\subsection{Instrumentation}

Pre-test and Post-test is administered to the participants. The pretest and posttests are reading comprehension tests which consist of 13 items. The reading passage is about 'Money and Happiness'. The items are as follow; matching the headings, T /True, F/ False, NG/ Not Given, reference questions, and multiple questions. After the treatment part, the post test was in the same format as well. 


\subsection{Data Analysis:}

SPSS is used in order to analyze the data, and graphically detailed analysis of the answers was shown in the result section of the study. Pair Sample statistics was used.

\section{Results}

The findings and the result of the current study will be illustrated in this section along with the framework of the research question. Sample Test was used in order to answer the research question due to several reasons. Firstly, the population of both classes from which the samples is drawn are normally distributed. Secondly, the populations have the similar variance and standard deviations. Lastly, the samples of the current study are from different populations which are random and independent. (Below see the frequencies for detailed information of the Experimental and Control Groups' Pre and Post Test.)

Table 1. Table of Frequency

\begin{tabular}{lllll} 
& ExperimentalPretest & ExperimentalPosttest & ComparisonPretest & ComparisonPosttest \\
\hline $\mathrm{N} \quad$ Valid & 20 & 20 & 20 & 20 \\
\cline { 2 - 5 } Missing & 0 & 0 & 0 & 0 \\
\hline Mean & 55.75 & 66.75 & 56.00 & 56.50 \\
\hline Median & 55.00 & 65.00 & 55.00 & 55.00 \\
\hline Mode & 55.00 & 65.00 & 50.00 & 55.00 \\
\hline Std. Devia. & 7.65 & 5.91 & 8.04 & 8.28 \\
\hline Variance & 58.61 & 34.93 & 64.73 & 68.68
\end{tabular}

Table 2 indicates the frequency both for ExperimentalPretest ExperimentalPosttest and ComparisonPretest ComparisonPosttest. The mean value is 55.75 for the ExperimentalPretest and 56.00 for the ComparisonPretest. However, the mean value for ExperimentalPosttest is 66.75, whereas the mean value for Comparison Post test 56.50 .

Table 2. The Table of Paired Sample Descriptive Statistic

\begin{tabular}{llllll}
\hline & & Mean & $\mathrm{N}$ & Std. Deviation & Std. Error Mean \\
\hline Pair 1 & ExperimentalPretest & 55.75 & 20 & 7.65 & 1.71 \\
\cline { 2 - 6 } & ExperimentalPosttest & 66.75 & 20 & 5.91 & 1.32 \\
\hline Pair 2 & ComparisonPretest & 56.00 & 20 & 8.04 & 1.79 \\
\cline { 2 - 5 } & ComparisonPosttest & 56.50 & 20 & 8.28 & 1.85 \\
\hline
\end{tabular}

Table 3 illustrates the Mean, Std. Deviation and the Std. Error Mean of the four scores for the both groups. As it can be easily understood from the above tables, the mean, median, mode, standard deviation and the variance of the both populations are quite similar. Table 2 has included more statistical value than the first table. 
Since the research question of the current research aimed to explore whether the retrieval vocabulary instruction has an effect on academic reading comprehension or not, Paired Sample is used.

Table 4: Paired Samples Test

\begin{tabular}{|c|c|c|c|c|c|c|c|c|c|}
\hline & & \multicolumn{5}{|c|}{ Paired Differences } & \multirow{3}{*}{ 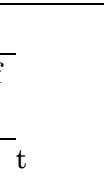 } & \multirow[b]{3}{*}{$\mathrm{df}$} & \multirow[t]{3}{*}{ Sig. (2-tailed) } \\
\hline & & \multirow[b]{2}{*}{ Mean } & \multicolumn{2}{|c|}{$\begin{array}{l}\text { Std. } \\
\text { Deviatio Std. Error }\end{array}$} & \multicolumn{2}{|c|}{$\begin{array}{l}95 \% \text { Confidence Interval of } \\
\text { the Difference }\end{array}$} & & & \\
\hline & & & $\mathrm{n}$ & Mean & Lower & Upper & & & \\
\hline Pair 1 & $\begin{array}{l}\text { ExperimentalPretest - } \\
\text { ExperimentalPosttest }\end{array}$ & -11.00 & 3.07 & .68 & -12.44 & -9.55 & -15.98 & 19 & .00 \\
\hline Pair 2 & $\begin{array}{l}\text { ComparisonPretest - } \\
\text { ComparisonPosttest }\end{array}$ & -.50 & 3.20 & .71 & -1.99 & .99 & -.69 & 19 & .49 \\
\hline
\end{tabular}

Table 4 helps distinguish the significance and the mean differences in the participants' scores. The number of participants in each condition is (N) 20. As it can be inferred the Sig (2-Tailed) value is 0.00 in the experimental group whereas the Sig (2-Tailed) value is 0.49 in the comparison group. These values are less than .05. Thus, it can be concluded that there is a statistically significant difference between the means which are not likely due to chance, and not likely due to the IV manipulation but due to the retrieval vocabulary instruction treatment. The Paired-Sample Statistics table indicated that the mean of the ExperimentalPretest - Experimental Posttest is greater than the mean for ComparisonPretest - ComparisonPosttest, since the values are -11.00 and -0.50 . When we look at the significance levels $(0.00-0.49$ and the means $(-11.00--0.50$. ) for both groups it can be said that there is a significant change between two test scores taken at different times by the same groups of participants. Thus, we can conclude that the treatment of the retrieval vocabulary instruction' was beneficial for the students since it increased their reading comprehension scores.

\section{Discussion}

The result of the current study is in accordance with the previous studies exploring the relationship between reading comprehension and vocabulary. To illustrate; in Nation's (2015) study, the significance of the extensive reading was emphasized, thus the article aimed to explore a different set of vocabulary learning principles that affect extensive reading by indicating much informative knowledge regarding extensive reading. The results are also consistent with those of Schmitt's (2011) studies that when the percentage of known words in a text increases the level of reading comprehension increases as well. Taken together, these studies support the notion that reading comprehension is highly related and integrated with vocabulary learning. Lastly, the findings of the current research confirm the association between vocabulary and the reading and also support the previous research. The findings of the research corroborate the ideas of Hirsch (2003) and Chall and Jacobs (2003) who 
found that readers should have knowledge of $90 \%$ of the words in the reading passage in order to have a high level of reading comprehension.

\section{Conclusion}

\subsection{Restatement of the problem}

This study aimed to explore the effects of retrieval vocabulary instruction on academic reading comprehension of 40 participants at the School of Foreign Languages at Istanbul Şehir University with the following research question; Does retrieval vocabulary instruction have an effect on academic reading comprehension? The independent variable is retrieval vocabulary instruction and the dependent variable is academic reading comprehension. The participants are selected following convenience sampling procedure from different sociocultural backgrounds. The procedure for the current study lasted eight weeks. The pre-test is administered in the first week of the module in order to see the academic reading comprehension level of the participants. The retrieval vocabulary instruction treatment procedure lasted seven weeks. Later post-test is administered in week eight so as to observe whether retrieval vocabulary instruction has any positive effect on academic reading comprehension or not. Paired T-Test is used with the help of SPSS in order to analyze the data. The findings of the current study indicate that when we look at the significance levels and the means for both of the groups, it can be said that there is a significant change between two of the test scores taken at different times by the same groups of participants. Thus, we can conclude that the treatment of 'the retrieval vocabulary instruction' was beneficial for the students since it increased their reading comprehension scores.

Regarding the contribution of the current study as previously mentioned, the existing literature on different reading strategies is detailed, but failed to address both academic reading comprehension and retrieval vocabulary instruction. Thus current study succeeded to fill the gaps in the filed in terms of academic reading comprehension. Although thorough research has been carried out on reading instructions, reading comprehension, and vocabulary input, no single study is reported which explores the relationship between both academic reading comprehension and retrieval vocabulary instruction. Much of the current literature on reading comprehension paid attention to the specific reading strategies, learner styles, and their influence rather than academic reading comprehension and retrieval vocabulary instruction.

Lastly, the result of the current study is in accordance with the previous studies exploring the relationship between reading comprehension and vocabulary.

\section{Implications}

The implications of the study differ since reading comprehension and teaching vocabulary has been a subject of many previous research. There are many studies in 
the literature on reading comprehension/ reading strategies and vocabulary; but to date, there have not been many studies on academic reading comprehension along with retrieval vocabulary instruction. Therefore, the current research is thought to be beneficial for the following theories regarding academic reading comprehension and retrieval vocabulary instruction. It is also helpful specifically for the retrieval strategies; Association Strategy- Same-Sounds Cue, Familiar-Word Cue, proposed by; German and Schwanke (2009). Laufer (2005) suggested that note cards that consist of part of speech, synonyms, antonyms, sample sentences are also beneficial for retrieval vocabulary instruction. Removal of the written input shared and split information tasks are thought to be found effective in retrieval vocabulary instruction (Nation, 2001).

There are few applications of the current research. Firstly, language teachers may use the 'retrieval vocabulary instruction' in their EFL classes to promote both the reading comprehension and the reading strategies of their students. The ones who are interested in teaching vocabulary with different techniques may also benefit from this study while preparing for their classes (PPT's and strategies). This study is conducted at a private university but this does not mean that state school teachers, public high school teachers or other educational institutions' teachers cannot benefit from this study.

\section{Limitations}

Despite the promising results, there are a few limitations of the study and several questions may remain unanswered at present. Firstly, gender was not taken into consideration since the retrieval vocabulary learning techniques might change due to gender differences, attention span and the retrieval memory of each individual. Secondly, the sample could be from different educational contexts since the current study is conducted in Istanbul Şehir University.

Another limitation is that the proficiency level of the participants might have affected the results since their language proficiency is considered to be around $\mathrm{C} 1$ according to the CEFR. One cannot assure if the result would be same when their level was different.

Lastly, it is not fully known whether it is the 'treatment of retrieval vocabulary instruction that has had an effect on reading comprehension or not. The increase in the reading scores for the experimental group may be due to other reasons that were not taken into consideration. Also, the current study is conducted with 40 students regardless of the participants' L1 since there were not only Turkish students in the research. It can be inferred that the findings would not be identical if all the participants were Turkish.

\section{Suggestions for Further Research}


Further research is required and another research should be undertaken to investigate the gender differences because of ranging retrieval long term strategies. There might be several differences in their vocabulary input along with the size.

There is an abundant room for further progress in determining how bilinguals would perform with different levels of proficiency regarding their long-term memory. In future investigations, it might also be possible to select the participants from different educational contexts to have more reliable results.

\section{References}

Baddeley, A. (1990). Human memory: Theory and Practice. Needham Heights, MA: Ally and Bacon.

Barcroft, J. (2015). Can retrieval opportunities increase vocabulary learning reading? Foreign Language Annals, 48(2), 236-249. doi: 10.1111/flan.12139

Brown, R., Waring, R., \& Donkaewbua, S. (2008). Incidental vocabulary acquisition from reading, reading-while-listening, and listening to stories. Reading in a Foreign Language, 20(2), 137-138.

Council of Europe. (2001). Common European framework of reference for languages: Learning, teaching, assessment. NA: Cambridge University Press.

Chall, J.S., \& Jacobs, V.A. (2003). Poor children's fourth-grade slump. American Educator, Retrieved from http://www.aft.org/pubs-reports/american_educator/spring2003/chall.html.

Chaury, P. (2015). The effects of strategy instruction on reading comprehension in English as a foreign language. Concordia Working Papers in Applied Linguistics, 6.

German, D. J., \& Schwanke, J. (2009). Teaching retrieval strategies also, dual focus vocabulary instruction for word-finding. Illinois Speech and Hearing Association (ISHA), Chicago, IL.

Grabe, W. (2009). Reading in a second language: Moving from theory to practice. New York: Cambridge University Press.

Grabe W. (2007). Key issues for L2 reading development. Northern Arizona University. Retrieved from http://www.nus.edu.sg/

Gürses, M. Ö. \& Bouvet E. (2016). Investigating reading comprehension and learning styles in relation to reading strategies in L2. Reading in a Foreign Language, 28(1), 20-42.

Kintsch, W. (1988). The role of knowledge in discourse comprehension: a constructionintegration model. American Psychological Review, 95(2), 163.

Laufer, B. (2005). Focus on form in second language vocabulary learning. EUROSLA Yearbook, 5, 223-250.

Min, Y. K. (2013). Vocabulary Acquisition: Practical Strategies for ESL Students. Journal of International Students, 3(1), 67. Retrieved from http://jistudents.org/

Nation, P. (2015). Principles guiding vocabulary learning through extensive reading. Reading in a Foreign Language, 27(1), 136. Retrieved from http://nflrc.hawaii.edu/rfl/April2015/discussion/nation.pdf

Nation, P. (2001). Learning Vocabulary in Another Language. NA: Cambridge University Press.

Hirsch, E.D. (2003). Reading comprehension requires knowledge - of words and the world: Scientific insights into the fourth-grade slump and the nation's stagnant comprehension scores. American Educator, American Federation of Teachers, 16. Retrieved from https://www.aft.org/sites/default/files/periodicals/AE_SPRNG.pdf 
Hu, M., \& Nation, P. (2000). Unknown vocabulary density and reading comprehension. Reading in a Foreign Language, 13(1), 403.

Perfetti, C., \& Stafura, J. (2014). Word knowledge in a theory of reading comprehension. Scientific Studies of Reading, Society for the Scientific Study of Reading, 18, 22-37. doi: 10.1080/10888438.2013.827687

Pulido, D. (2004). The relationship between text comprehension and second language incidental vocabulary acquisition: A matter of topic familiarity? Language Learning, 54(3), $469-523$.

Senoo, Y., \& Yonemoto, K. (2014). Vocabulary learning through extensive reading. The Canadian Journal of Applied Linguistics, 17(2), 1-22.

Shen, Z. (2013). The effects of vocabulary knowledge and dictionary use on EFL reading performance: English Language Teaching; Canadian Center of Science and Education, 6(6).

Schmitt, N., Jiang, X., \& Grabe, W. (2011). The percentage of words known in a text and reading comprehension. The Modern Language Journal, 95, 26-43.

Takac, V. P. (2008). Vocabulary learning strategies and foreign language acquisition. Clevedon, UK: Multilingual Matters.

Thorne, G. (2006). 10 strategies to enhance students' memory. Metarie, LA: Center for Development and Learning. Retrieved from http://www.cdl.org/resourcelibrary/ articles/memory_strategies_May06.php

TESOL International Associations (2017). Retrieved from http://www.tesol.org/docs/books/bk_ELTD_Reading_998

TESOL International Associations (2017). Retrieved from http://www.tesol.org/docs/books/bk_ELTD_Vocabulary_974

Williams, J. (2010). Reading comprehension, learning styles, and seventh-grade students, (Doctoral dissertation), Retrieved from ProQuest Dissertations and Theses database, UMI No: 3397106.

\section{Appendix A. Vocabulary Flashcards/ PPT's (Some Samples)}
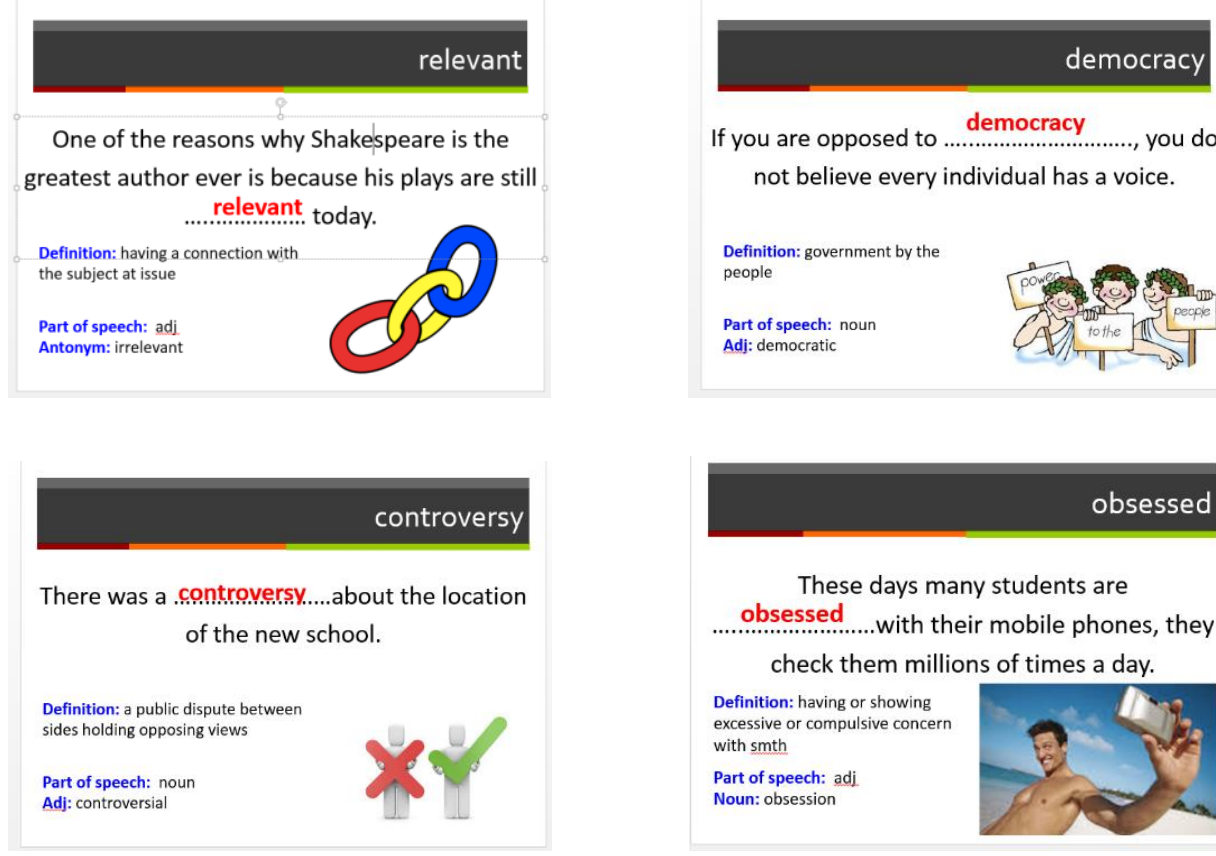

These days many students are obsessed

check them millions of times a day.

Definition: having or showing with smth

Part of speech: adj.

Noun: obsession

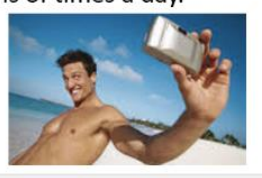




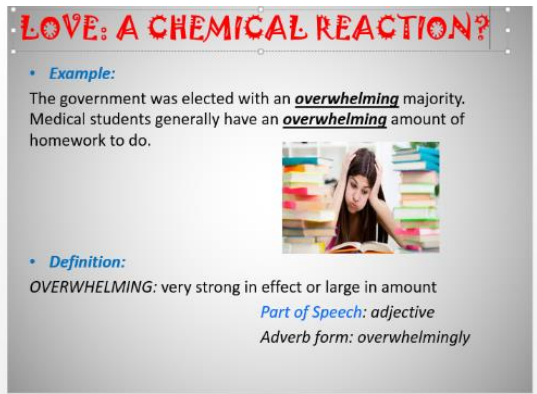

sense ( $(v)$

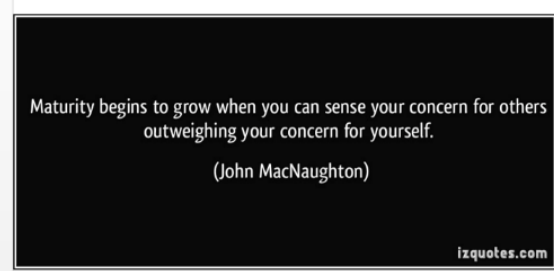

conventional

Definition: following traditional forms and genres:

Part of speech: adjective

Example: Rather than followin workers use modern methods.

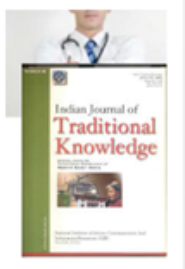

convince ( $v$ )

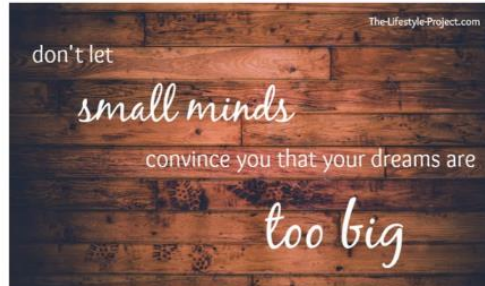

\section{Appendix B. The List of Target Vocabulary}

\begin{tabular}{|lcc|}
\hline & & \\
Assume & Conventional & Satisfaction \\
Obsession & Shortcoming & Willing \\
Judge & Approximately & Demand \\
Sense & Impression & Convince \\
Expectation & Overwhelming & Sufficient \\
Democracy & Contradict & Investment \\
\hline
\end{tabular}




\section{Appendix C. Reading Comprehension Test}

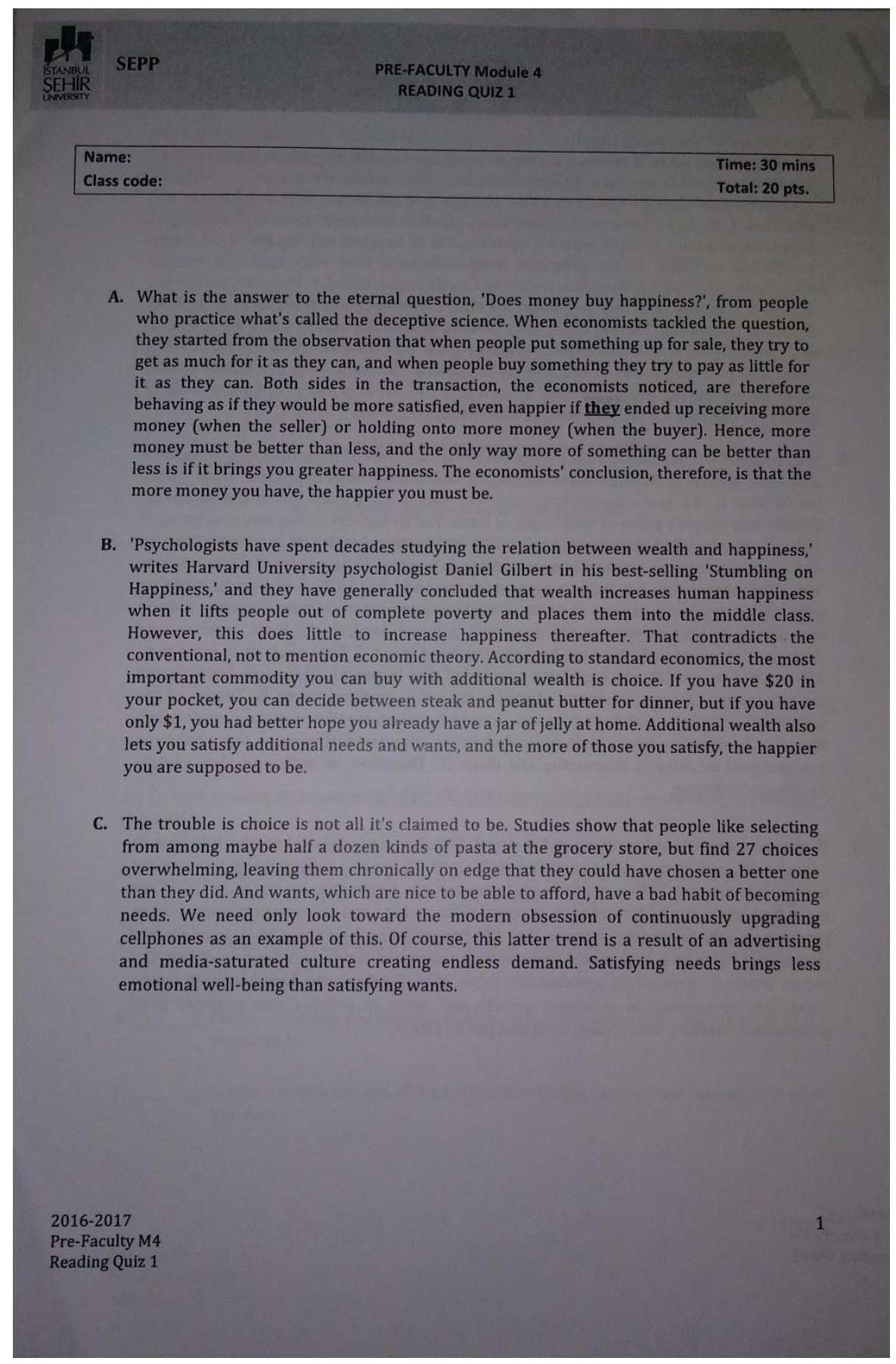


D. The nature of how much happiness money can buy is difficult to measure. It buys lots more happiness when it moves a person from being poor and into middle-class comfort, but hardly any more joy when it elevates you from, for example, millionaire to billionaire. This fact comes through clearly in global surveys that ask people how content they feel with their lives. In a typical survey, people are asked to rank their sense of well-being or happiness on a scale of 1 to 7 , where 1 means 'not at all satisfied with my life' and 7 means 'completely satisfied.' Of the American multimillionaires who responded, the average happiness score was 5.8. Homeless people in Calcutta came in at 2.9. However, before you assume that money does buy happiness, the others who also rated themselves around 5.8 should be considered. The Inu of northern Canada, who do not exactly lead a life of luxury, and the cattle-herding Masai of Kenya, whose grass huts have no electricity or running water also rate themselves at this level of happiness. This helps to prove Gilbert's point about money buying happiness only when it lifts you out of poverty. In homes made of garbage in Calcutta the people surveyed rate themselves at 4.6.

E. International studies monitoring changes in reported levels of happiness over time have also been shown to be false when looking at the 'money buys happiness' claim. Since World War II, the gross domestic product per capita has tripled in the United States. Despite this people's sense of well-being, as measured by surveys asking some variation of 'Overall, how satisfied are you with your life?' has barely moved. This is strange because due to economic boom, one would expect to see an increase in happiness of three times, as well. Moreover, Japan has had an even more meteoric rise in GDP per capita since its postwar misery, but measures of national happiness remain unchanged. Western Europe too, during its long postwar boom, according to social psychologist Ruut Veenhoven of Erasmus University in Rotterdam, has seen the same trend. A 2004 analysis of more than 150 studies on wealth and happiness concluded that 'economic indicators have glaring shortcomings' as approximations of well-being across nations, wrote Ed Diener of the University of Illinois. 'Although economic output has risen steeply over the past decades, there has been no reported rise in things like satisfaction and furthermore, there has been a substantial increase in depression and distrust.' Therefore, as indicators they remain insufficiently strong.

F. If money doesn't buy happiness, what does? Grandma was right when she told you to value health and friends, not money and stuff. Or as Diener and Seligman put it, once your basic needs are met, 'differences in well-being are less frequently due to income, and are more frequently due to factors such as social relationships and enjoyment at work.' Other researchers add fulfillment, a sense that life has meaning, belonging to civic and other groups and living in a democracy that respects individual rights and the rule of law. If a nation wants to increase its population's sense of well-being, says Veenhoven, it should make 'less investment in economic growth and more in policies that promote good governance, liberties, democracy, trust and public safety.' 


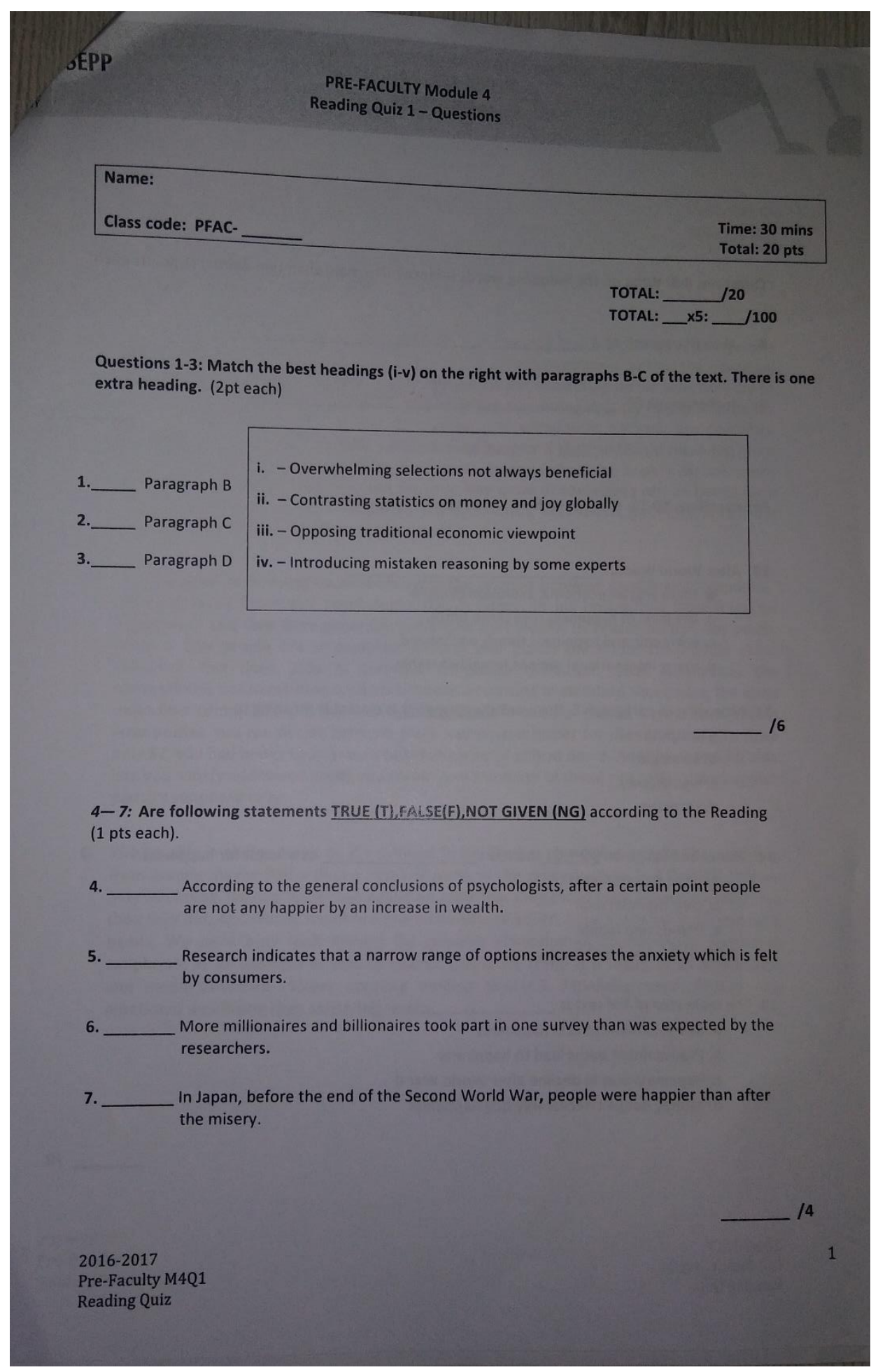




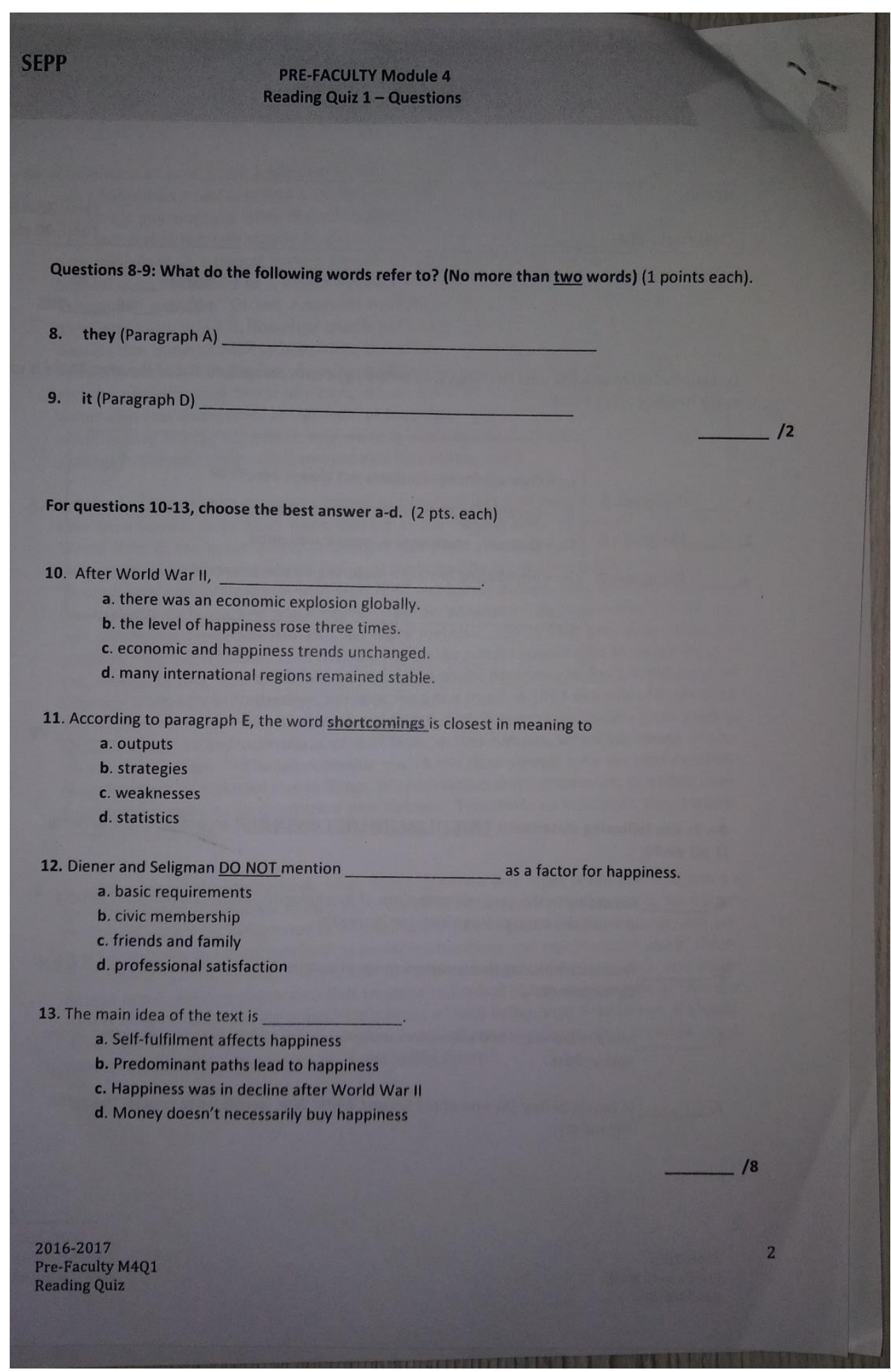

\section{Copyrights}

Copyright for this article is retained by the author(s), with first publication rights granted to the Journal.

This is an open-access article distributed under the terms and conditions of the Creative Commons Attribution license (CC BY-NC-ND) (http://creativecommons.org/licenses/by-nc-nd/4.0/). 